\title{
RESPOSTA IMUNE-HUMORAL DE BÚFALOS (Bubalus bubalis) CONTRA Anaplasma marginale (THEILER, 1910)
}

\author{
RICARDO A. GOMES ${ }^{1}$; ROSANGELA Z. MACHADO ${ }^{1}$; WILMA A. STARKE-BUZETTI ${ }^{2}$; MARIAA. BONESSO ${ }^{3}$
}

\begin{abstract}
GOMES, R.A.; MACHADO, R.Z.; STARKE-BUZETTI, W.A.; BONESSO M.A. [Immunehumoral response of water buffalo (Bubalus bubalis) against Anaplasma marginale (Theiler, 1910).] Resposta imune-humoral de búfalos (Bubalus bubalis) contra Anaplasma marginale (Theiler, 1910). Revista Brasileira de Parasitologia Veterinária Veterinária, v.17, n. 2, p. 73-80, 2008. Departamento de Patologia Veterinária, Faculdade de Ciências Agrárias e Veterinárias, Universidade Estadual Paulista “Julio de Mesquita Filho”, Campus de Jaboticabal, Via de Acesso Prof. Paulo Donato Castellane s/n, Jaboticabal, SP 14884-900, Brasil. E-mail: starke@bio.feis.unesp.br

The aim of the present study was to analyze the humoral-immune response of water buffalo (Bubalus bubalis) naturally infected against Anaplasma marginale. For this work, colostrums/milk and blood samples were sequentially collected from buffalo cows prior and after partum for a period of 335 days and from buffalo calves from birth to 365 days after. The antibodies in the colostrums/milk and serum samples of these animals were determined using an ELISA indirect method and the data were analyzed as a mean of a group of animals with the matched ages during the period of 1999/2000 or individually during the year of 2005. The data from animals analyzed in group showed that the antibodies against $A$. marginale were in low concentration (below the cut off point: D.O. $=0.265$ and ELISA levels, EL $\geq 3$ ), in the sera of buffalo, during the first 90 and 105 days, respectively for cows and calves. Then, the levels of antibodies in the serum samples of buffalo calves, slightly raised to above the cut off point and kept in higher levels up to approximately 365 days after birth, indicating active acquired immunity. Furthermore, when the animals were individually examined, the buffalo cows showed high antibody levels in the colostrums, but low levels in the blood stream during the first seven days post-partum, suggesting antibody transference from blood to mammary gland $\mathrm{n}$ addition to that, buffalo calves showed high antibody levels during the first 24 hours after suckling colostrum, indicating a colostral passive immunity. By conclusion, the buffalos were able to arm a humoral immune response against $A$. marginale and were considered reservoir of this parasite.
\end{abstract}

KEY WORDS: Anaplasma marginale, water buffalo, immune-humoral.

\section{RESUMO}

O objetivo do presente estudo foi analisar a resposta imune humoral anti-Anaplasma marginale em búfalos (Bubalus bubalis) naturalmente infectados. Amostras de soro e de colostro/leite coletadas de búfalas adultas por um período de 335 dias após o parto e de soros dos seus bezerros do nascimento até 365 dias de

\footnotetext{
${ }^{1}$ Departamento de Patologia Veterinária, Faculdade de Ciências Agrárias e Veterinárias, Universidade Estadual Paulista "Julio de Mesquita Filho" (Unesp), Campus de Jaboticabal, Via de Acesso Prof. Paulo Donato Castellane s/n, Jaboticabal, SP 14884-900. Bolsista do CNPq. E-mail: cosmogomes@hotmail.come zacarias@fcav.unesp.br

${ }^{2}$ Departamento de Biologia e Zootecnia, Faculdade de Engenharia, Unesp, Campus Ilha Solteira, E-mail: starke@bio.feis.unesp.br

${ }^{3}$ Bolsista CNPq (Programa Apoio Técnico à Pesquisa).
}

vida, foram usadas para a realização do método ELISA indireto. Os dados foram analisados como a média de um grupo de animais, em diferentes faixas etárias, durantes os anos de 1999/2000 e individualmente (duas búfalas e dois bezerros), no ano de 2005. Os soros dos animais analisados em grupos apresentaram títulos de anticorpos abaixo do ponto de corte (D.O. = 0,265 e NE $\geq 3$ ) durante os primeiros 90 e 105 dias, para as búfalas e para os seus bezerros, respectivamente, mas em seguida, elevaram-se para níveis acima do ponto de corte até o final do trabalho, ou seja, um ano após, indicando uma imunidade ativa adquirida. Das duas búfalas examinadas individualmente, os anticorpos colostrais foram detectados em altos níveis, mas os sorológicos em baixos níveis durante os primeiros sete dias após o parto, sugerindo uma transferência de anticorpos do soro para a glândula mamária. Da mesma forma, os dois bezerros tiveram títulos de anticorpos 
detectáveis já nas primeiras 24 horas após mamarem o colostro, indicando uma imunidade colostral passiva Em conclusão, os búfalos desenvolveram uma resposta imune humoral específica contra A. marginale e foram considerados portadores deste parasita.

PALAVRAS-CHAVE: Anaplasma marginale, búfalos, imune-humoral.

\section{INTRODUÇÃO}

O búfalo (Bubalus bubalis) é originário da Ásia e são conhecidas pelo menos 12 raças indianas, sendo que no Brasil, as mais comuns são Murrah, Jaffarabadi e Mediterrâneo. São ditos como animais rústicos e bem adaptados ao nosso meio, possuem grande potencial zootécnico para os seus produtos carne e leite, bem como grande valor agregado nos seus subproduto, como o couro (FRANZOLIN-NETO, 1993).

O búfalo também alberga Boophilus microplus (STARKE et al., 1985, 1994), Haematobia irritans (ALLINGHAM et al.,1994) e Stomoxys calcitrans (POTGIETER et al., 1981) que por sua vez, espoliam-no e podem transmitir Anaplasma marginale (MOHAN, 1968) e outros agentes etiológicos como Babesia bovis e $B$. bigemina que também podem ser transmitidos aos búfalos por ixodídeos (COSTA et al., 1997) e serem responsáveis pela enfermidade caracterizada como Tristeza Parasitária Bubalina (TPBu).

A anaplasmose é uma das hemoparasitoses mais prevalentes nos bovinos (BARBET et al., 1987; PALMER, 1989). No Brasil, A. marginale é encontrado em bovinos de várias regiões do país (KANO et al., 2002). Relatos sobre Anaplasmose em búfalos no Brasil foram realizados por Franzolin-Neto et al. (1989) e Gomes et al. (2006).

Embora a anaplasmose clínica não seja muito freqüente em búfalos, Srivastava e Ahluwalia (1974) descreveram os sinais clínicos de um caso como: anemia hemolítica primária que se acentuava conforme aumentava a proporção de eritrócitos infectados. No entanto, na maioria das vezes, ocorria baixa parasitemia e com a doença evoluindo para inapetência, depressão, parada da ruminação, emagrecimento, fezes escuras, taquicardia, taquipnéia, constipação intestinal e mucosas ictéricas e pálidas. Em ensaios experimentais com bezerros búfalos, Sharma (1987) detectou anticorpos anti-A. marginale entre 27 a 32 dias após a infecção, e observou que o parasito não era muito agressivo ao hospedeiro, mas o búfalo podia ser um reservatório da infecção.

Alguns levantamentos epidemiológicos têm mostrado uma relação direta da piroplasmose em búfalos com a infestação de carrapatos. Desta forma, Miranpuri (1988) relatou que 6,2\% e $14,9 \%$ dos búfalos estavam infectados com $A$. marginale em duas localidades da Índia, respectivamente, onde na primeira localidade, B. microplus representava $75,3 \%$ da população de ixodídeos identificados nestes animais. Contudo, o estudo realizado no Paquistão por Rajput et al. (2005) em 250 búfalos evidenciou que $30 \%$ destes animais estavam infectados com Anaplasma sp. mesmo com baixa infestação de carrapatos.
Considerando a escassez de trabalhos sobre A. marginale em búfalos, este trabalho teve como objetivo estudar a resposta imune humoral dos búfalos contra $A$. marginale por meio do teste imunoenzimático ELISA indireto, utilizando-se colostros e soros de búfalas adultas coletados sequencialmente do periparto aos 335 dias pós-parto e de soros de seus bezerros búfalos no primeiro ano de vida.

\section{MATERIAL E MÉTODOS}

\section{Local, animais e manejo}

Os trabalhos de campo relacionados a este estudo foram executados na Fazenda Experimental de Ensino e Pesquisa da Universidade Estadual Paulista "Julio de Mesquita Filho (UNESP), situada à margem direita do Rio Paraná, no município de Selvíria, Estado de Mato Grosso do Sul, no período de janeiro de 1999 a março de 2000 e durante o ano de 2005.

Foram utilizados para a presente pesquisa, bezerros búfalos, fêmeas e machos mestiços (Murrah x Mediterrâneo), com idades variando de recém-nascidos até 12 meses de idade e búfalas adultas, próximo ao parto, recém-paridas e após o parto, durante o período de um ano, acompanhadas com seus respectivos bezerros.

O regime de criação destes animais foi extensivo, onde os bezerros búfalos permaneceram junto com as mães até o desmame, pois as búfalas não eram ordenhadas. Os búfalos foram mantidos em pastagem formada por capim braquiária (Brachiaria decumbens) e era constituído por 40 animais que mantinham contato com o rebanho bovino da mesma fazenda. A reprodução era feita através de monta natural, com nascimentos concentrados entre janeiro a abril de cada ano.

\section{Amostras de Soro e Colostro}

As amostras de soro e colostro foram obtidas a partir da seroteca pertencente ao Laboratório de Imunoparasitologia do Departamento de Biologia e Zootecnia da UNESP-Campus de Ilha Solteira provenientes de animais pertencentes ao rebanho bubalino descrito acima. As amostras de soro e colostro coletadas no período de 1999/2000 foram agrupadas de acordo com a faixa etária ou cronológica e os resultados foram representados como a média do grupo, com número de animais variando de 4 a 12. Para compor esta seroteca, amostras de sangue e colostro/leite foram coletadas sequencialmente por um período aproximado de um ano.

As amostras de sangue dos bezerros foram coletadas no dia do nascimento, antes de receber o colostro e no decorrer das primeiras 24 horas de amamentação. Seguiu-se então, obtendo-se as amostras semanalmente até que os animais completassem 60 dias, quinzenalmente até 180 dias e mensalmente até 365 dias. As amostras de sangue das búfalas foram coletadas antes e após o parto. Após o parto, as coletas foram realizadas simultaneamente com as dos bezerros. As amostras de colostro/leite das búfalas foram coletadas, através de ordenha manual no dia do parto e semanalmente por um período de 60 dias, sempre no mesmo dia das coletas de sangue. 
No ano de 2005, decidiu-se por complementar o estudo analisando-se quatro animais individualmente e, para isso colheu-se seqüencialmente amostras de sangue e colostro de duas búfalas e seus respectivos bezerros, mas durante um período de aproximadamente cinco meses com intervalos de uma a duas semanas, a partir do parto e/ou do nascimento. A coleta, o processamento e o acondicionamento das amostras de soro e colostro/leite foram realizados mediante a metodologia descrita por Souza (2000).

\section{Ensaio imunoenzimático - ELISA indireto}

O teste imunoenzimático ELISA indireto foi realizado no Laboratório de Imunodiagnóstico do Departamento de Patologia Animal da Faculdade de Ciências Agrárias e Veterinárias da UNESP.

Para detecção da resposta imune humoral dos animais naturalmente infectados por A. marginale, amostras de soro sangüíneo e colostro/leite foram submetidas ao ELISA-indireto segundo Machado et al. (1997) para B. bovis, adaptado para A. marginale. Como controles positivos, foram utilizados soros de bovinos e de búfalos mantidos a campo com alto título de anticorpos anti- A.marginale e como controles negativos, amostras de soros de bezerros búfalos sorologicamente negativos, ou em jejum colostral, no primeiro dia pós-nascimento.

A leitura dos resultados foi realizada em leitor de ELISA, com filtro a comprimento de onda de 405nm.
A atividade enzimática de cada soro/colostro no teste ELISA indireto foi calculada mediante determinação de seu valor A/P. Este valor A/P (amostra em relação ao referencial positivo) de cada amostra de soro foi calculado levando-se em consideração, os soros de referência positiva e negativa, de acordo com a seguinte fórmula:

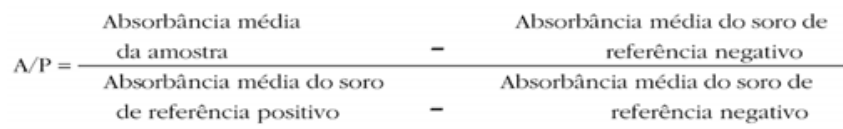

Os valores A/P foram agrupados em níveis ELISA (NE), que variaram de zero a nove (0 - 9). A amplitude máxima dos NE zero foi determinada pela média dos valores em absorbância de soro de animais não imunes contra $A$. marginale (soro de referência negativa), acrescido de dois desvios padrão da média correspondente conforme Machado et al. (1997). A partir deste limite, os intervalos entre os outros níveis no ELISA foram acrescidos de 35\% cada. O ponto de corte do teste foi determinado usando a média da densidade óptica (DO) de soros e colostros/leite de animais negativos para A. marginale multiplicado por 2,5. Animais com média sorológica com D. Os acima de 0,265 ( $\mathrm{NE} \geq 3$ ) e média colostral acima de $0,435(\mathrm{NE}=3)$ foram considerados positivos.

\section{RESULTADOS E DISCUSSÃO}

Os resultados referentes à detecção de anticorpos anti-A. marginale pelo teste ELISA indireto realizado nos colostros e

Tabela 1. Anticorpos anti-Anaplasma marginale pelo teste ELISA realizado em soros e colostros de búfalas adultas e soros de bezerros búfalos a partir do parto e nascimento, respectivamente. Resultados em A/P (Amostra/Positivo) e NE (Níveis Elisa). Selvíria, MS, 1999/2000.

\begin{tabular}{|c|c|c|c|c|c|c|c|c|c|}
\hline \multirow{4}{*}{$\begin{array}{c}\text { Dias } \\
\text { Pós-Parto/ } \\
\text { Nascimento }\end{array}$} & \multicolumn{9}{|c|}{ Anticorpos anti-Anaplasma marginale } \\
\hline & \multicolumn{6}{|c|}{ Búfalas } & \multirow{2}{*}{\multicolumn{3}{|c|}{$\frac{\text { Bezerros Búfalos }}{\text { (Soro) }}$}} \\
\hline & \multicolumn{3}{|c|}{ Soro } & \multicolumn{3}{|c|}{ Colostro } & & & \\
\hline & $\mathrm{N}$ & A/PMédia $\pm \mathrm{DP}$ & $\mathrm{NE}$ & $\mathrm{N}$ & A/PMédia $\pm \mathrm{DP}$ & $\mathrm{NE}$ & $\mathrm{N}$ & A/PMédia \pm DP & $\mathrm{NE}$ \\
\hline$-1-14$ & 7 & $0,279 \pm 0,065$ & 3 & & & & & & \\
\hline $1^{*}$ & 10 & $0,177 \pm 0,066$ & 3 & & & & 10 & $0,000 \pm 0,000^{*}$ & 0 \\
\hline 1 & 10 & $0,177 \pm 0,066$ & 1 & 10 & $0,107 \pm 0,170$ & 0 & 9 & $0,177 \pm 0,079$ & 2 \\
\hline $2-7$ & 12 & $0,182 \pm 0,055$ & 1 & 10 & $0,058 \pm 0,082$ & 0 & 9 & $0,143 \pm 0,067$ & 1 \\
\hline $8-15$ & 10 & $0,158 \pm 0,033$ & 0 & 10 & $0,066 \pm 0,175$ & 0 & 9 & $0,152 \pm 0,060$ & 2 \\
\hline $16-30$ & 10 & $0,182 \pm 0,063$ & 1 & 10 & $0,028 \pm 0,046$ & 0 & 9 & $0,116 \pm 0,050$ & 1 \\
\hline $31-45$ & 11 & $0,167 \pm 0,053$ & 0 & 10 & $0,001 \pm 0,043$ & 0 & 10 & $0,163 \pm 0,084$ & 2 \\
\hline $46-60$ & 10 & $0,136 \pm 0,033$ & 0 & 10 & $0,184 \pm 0,273$ & 0 & 10 & $0,137 \pm 0,052$ & 1 \\
\hline $61-75$ & 10 & $0,133 \pm 0,058$ & 0 & & & & 10 & $0,119 \pm 0,060$ & 1 \\
\hline $75-90$ & 8 & $0,162 \pm 0,036$ & 1 & & & & 10 & $0,180 \pm 0,089$ & 2 \\
\hline $91-105$ & 10 & $0,550 \pm 0,260$ & 5 & & & & 10 & $0,157 \pm 0,058$ & 2 \\
\hline $106-120$ & 7 & $0,516 \pm 0,180$ & 5 & & & & 10 & $0,257 \pm 0,143$ & 3 \\
\hline $121-135$ & 9 & $0,475 \pm 0,148$ & 2 & & & & 10 & $0,244 \pm 0,1-5$ & 3 \\
\hline $136-150$ & 4 & $0,340 \pm 0,072$ & 4 & & & & 10 & $0,281 \pm 0,088$ & 4 \\
\hline $151-165$ & 10 & $0,423 \pm 0,195$ & 4 & & & & 8 & $0,266 \pm 0,124$ & 3 \\
\hline $166-180$ & 6 & $0,327 \pm 0,110$ & 3 & & & & 8 & $0,303 \pm 0,086$ & 4 \\
\hline $181-210$ & 11 & $0,416 \pm 0,177$ & 4 & & & & 10 & $0,287 \pm 0,136$ & 4 \\
\hline $211-241$ & 11 & $0,501 \pm 0,216$ & 5 & & & & 10 & $0,406 \pm 0,188$ & 5 \\
\hline $242-272$ & 10 & $0,476 \pm 0,147$ & 5 & & & & 10 & $0,446 \pm 0,278$ & 5 \\
\hline $273-303$ & 10 & $0,402 \pm 0,183$ & 4 & & & & 8 & $0,439 \pm 0,189$ & 5 \\
\hline $304-335$ & 11 & $0,300 \pm 0,174$ & 3 & & & & 7 & $0,193 \pm 0,034$ & 2 \\
\hline $336-365$ & & & & & & & 8 & $0,313 \pm 0,115$ & 4 \\
\hline
\end{tabular}

$\mathrm{N}$ : Número de animais. DP: Desvio padrão da média. -1-14 dias: dias antes do parto. $1^{*}$ : dia do nascimento antes de mamar o colostro. Ponto de Corte $\geq 3$ 


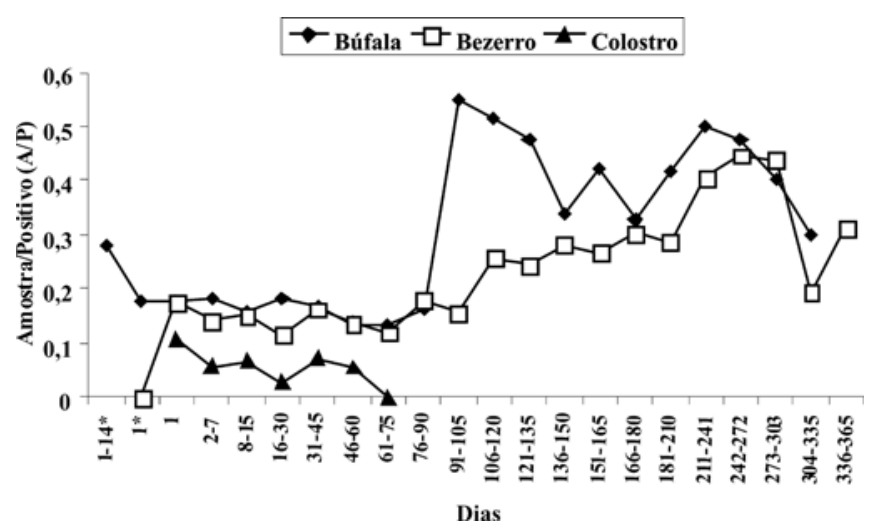

Figura 1. Anticorpos anti-Anaplasma marginale no colostro/leite e no soro de búfalas adultas $(n=4$ a 12$)$ e de seus respectivos bezerros $(n=7$ a 10), realizado em amostras coletadas sequencialmente com intervalos semanais, quinzenais e mensais durante um período de 1 a 365 dias após o parto/ nascimento, respectivamente. 1-14* = dias antes do parto e $1^{*}=$ dia do nascimento antes do bezerro mamar o colostro. Selvíria, MS, 1999/2000.

nos soros das búfalas adultas e de seus bezerros em condições naturais na região de Ilha Solteira, SP, estão representados nas Tabela 1 a 3 e Figuras 1 a 3.

Na Tabela 1 e Figura 1, observa-se o perfil dos níveis médios de anticorpos anti-A. marginale colostrais e sorológicos das búfalas, do periparto aos 335 dias pós-parto, e sorológicos dos bezerros do nascimento aos 365 dias de vida. Nas búfalas, os anticorpos sorológicos foram inicialmente detectados antes do parto (14 dias) e no dia do parto, mas estes declinaram a seguir a níveis inferiores ao ponto de corte (NE $\geq 3$ ) e mantiveram-se assim por aproximadamente 90 dias. Resultados semelhantes foram obtidos por Pacheco et al. (2004) em bovinos, onde os níveis de anticorpos séricos antiA. marginale caíram no peri-parto e permaneceram assim por até 60 dias pós-parto. O declínio na curva de anticorpos, neste período pode ser em função da transferência de anticorpos do sangue para o colostro (SASAKI et al., 1976; NEWBY; BOURNE, 1977) ou por uma imunodepressão pós-parto (LLOYD, 1983; AMERASINGHE et al., 1994) ou pela somatória de ambos os fatores.

A partir de 91 dias, estes anticorpos elevaram-se no soro, com NE variando de 3 a 5 até os 335 dias, na maioria das amostras examinadas, quando as búfalas já estavam próximas do parto seguinte, sugerindo que elas conseguiram manter o equilíbrio imunológico, possivelmente em função de novos desafios antigênicos oriundos de carrapatos infectados ou vetores mecânicos presentes nas pastagens. Carrapatos são considerados importantes vetores biológicos da A. marginale para bovinos (KESSLER, 2001; KOCAN et al., 2004). Boophilus microplus é um carrapato monoxênico, mas os adultos, principalmente os machos, podem migrar entre os animais por contatos físicos, principalmente entre mães e filhos e animais em atividades sexuais facilitando a transmissão transestadial e intraestadial de A. marginale de um animal a outro (CONNELL, 1974; MASON; NORVAL, 1981; KESSLER,
2001). Além disso, a presença de DNA de A. marginale em larvas originárias de fêmeas ingurgitadas de $B$. microplus (SHIMADA et al., 2004) sugere a possibilidade de transmissão transovariana aumentando em muito o risco da manutenção da infecção entre os animais, principalmente através das larvas. Em pesquisas realizadas por Starke et al. (1985 e 1995), B. microplus apresentou pouca adaptabilidade aos búfalos, pois $75 \%$ das contagens de carrapatos realizadas nestes animais foram representadas por larvas, e destas, poucas conseguiam alcançar o estádio adulto. Desta forma, as larvas juntamente com os poucos estádios de ninfas e adultos, podem ter expressiva participação na transmissão de $A$. marginale no rebanho bubalino. Além do carrapato, as moscas hematófagas do gênero Tabanus, podem também ter importância na transmissão de A. marginale. Mais recentemente De La Fuente et al. (2005) detectaram DNA de A. marginale na probóscide de tabanídeos o que sugere serem os tabanídeos importantes vetores mecânicos deste agente etiológico para búfalos por viverem estes em regiões alagadas.

Ainda na Tabela 1 e Figura 1 observa-se que os anticorpos anti-A. marginale no colostro das búfalas encontravam-se em concentração abaixo do ponto de corte por todo o período analisado, não transferência de anticorpos, pelo menos neste grupo de animais. Esta não transferência de anticorpos ficou também evidente nos soros dos bezerros, pois, estes animais apresentaram níveis de anticorpos inferiores ao ponto de corte (NE = 1 a 2) do nascimento aos 105 dias de vida. Resultados semelhantes foram obtidos por Gale et al. (1992) e Pacheco et al. (2005) que verificaram baixos teores de imunoglobulinas séricas em bezerros do nascimento aos 45 dias de vida, indicando também uma falha na transferência da imunidade passiva. Consequentemente, o período do nascimento aos 105 dias de idade torna-se crítico, pois os bezerros encontram-se imunologicamente desprotegidos e mais vulneráveis à infecção natural por carrapatos e consequentemente Anaplasma.

Em seguida, os bezerros búfalos começaram a apresentar anticorpos em NE acima do ponto de corte, somente a partir de 105 dias de idade e mantiveram-se altos até a idade de 365 dias (NE variando de 3 a 5). Estes anticorpos, possivelmente foram ativamente produzidos após infecção natural por $A$. marginale. Concordantemente, Pacheco et al. (2004) verificaram para bovinos, que a maioria dos bezerros teve níveis de anticorpos séricos altos somente a partir dos 105 dias de idade, mas com PCR positiva para A. marginale pela primeira vez aos 45 dias de idade, indicando uma infecção natural por este agente. Andrade et al. (2001) e Yoshihara et al. (2003) verificaram que mesmo sem proteção colostral, mas com o aumento do parasitismo por carrapato, aumenta também os níveis séricos de anticorpos com a idade, indicando a produção ativa de anticorpos específicos contra $A$. marginale em função da infecção adquirida após o nascimento. Esta imunidade pode perdurar por longos períodos, ou seja, por até cinco anos, dependendo da taxa de infestação diária de carrapatos infectados (FARIAS; LEMOS, 2001). Isto explica porque os búfalos mesmo com carga parasitária baixa por carra- 
patos, apresentam anticorpos anti-Anaplasma no soro sanguíneo, significando uma imunidade duradoura, possivelmente em função da persistência de uma infecção latente.

Para os animais analisados individualmente no ano de 2005 (Tabelas 2 e 3), verificou-se que tanto as búfalas quanto os seus bezerros, embora com alguma variabilidade individual, apresentaram o mesmo padrão da resposta imune humoral. As duas búfalas; de número 130 (Tabela 2 e Figura 2) e 134 (Tabela 3 e Figura 3) apresentaram altos níveis de anticorpos séricos antes

Tabela 2. Anticorpos anti-Anaplasma marginale pelo teste ELISA em amostras de soros e colostros da búfala 130 e soros de seu bezerro (365), coletadas sequencialmente a partir do parto/nascimento, respectivamente. Resultados em A/P (Amostra/Positivo) e NE (Níveis ELISA). Selvíria, MS, 2005.

\begin{tabular}{|c|c|c|c|c|c|c|}
\hline \multirow{4}{*}{$\begin{array}{c}\text { Dias } \\
\text { Pós-Nasci- } \\
\text { mento/Parto }\end{array}$} & \multicolumn{6}{|c|}{ Anticorpos anti-Anaplasma marginale - Valores A/P } \\
\hline & \multicolumn{4}{|c|}{ Búfala 130} & \multirow{2}{*}{\multicolumn{2}{|c|}{$\begin{array}{c}\text { Bezerro } 365 \\
\text { Soro }\end{array}$}} \\
\hline & \multicolumn{2}{|c|}{ Colostro } & \multicolumn{2}{|c|}{ Soro } & & \\
\hline & $\mathrm{A} / \mathrm{P}$ & $\mathrm{NE}$ & $\mathrm{A} / \mathrm{P}$ & $\mathrm{NE}$ & $\mathrm{A} / \mathrm{P}$ & $\mathrm{NE}$ \\
\hline-14 & & & 0,534 & 6 & & \\
\hline $1^{*}$ & 1,571 & 7 & 0,250 & 3 & $0,069 *$ & $0^{*}$ \\
\hline 7 & 0,703 & 3 & 0,250 & 3 & 0,188 & 2 \\
\hline 12 & 0,329 & 2 & 0,340 & 4 & 0,180 & 2 \\
\hline 21 & 0,101 & 0 & 0,444 & 5 & 0,265 & 3 \\
\hline 27 & 0,101 & 0 & 0,430 & 5 & 0,385 & 5 \\
\hline 34 & 0,089 & 0 & 0,114 & 1 & 0,238 & 3 \\
\hline 39 & 0,121 & 0 & 0,260 & 3 & 0,238 & 3 \\
\hline 49 & 0,034 & 0 & 0,344 & 4 & 0,236 & 3 \\
\hline 63 & 0,142 & 0 & 0,346 & 4 & 0,230 & 3 \\
\hline 70 & & & 0,181 & 2 & 0,123 & 1 \\
\hline 76 & & & 0,122 & 1 & 0,331 & 4 \\
\hline 105 & & & 0,490 & 6 & 0,216 & 3 \\
\hline 112 & & & 0,272 & 4 & 0,204 & 3 \\
\hline 119 & & & 0,539 & 6 & 0,177 & 2 \\
\hline 148 & & & 0,441 & 5 & 0,151 & 2 \\
\hline 161 & & & 0,261 & 3 & 0,167 & 2 \\
\hline
\end{tabular}

$\mathrm{N}$ : Número de animais. DP: Desvio padrão da média. -1-14 dias: dias antes do parto. $1^{*}$ : dia do nascimento antes de mamar o colostro. Ponto de Corte $\geq 3$.

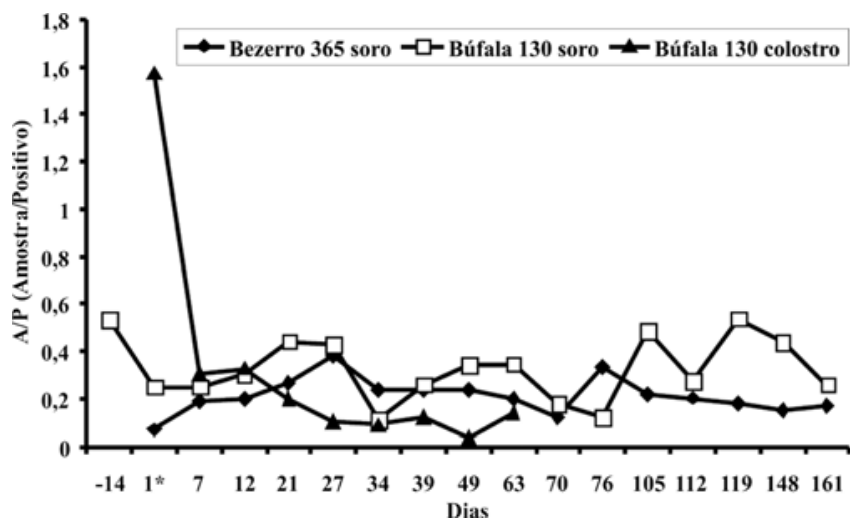

Figura 2. Anticorpos anti-Anaplasma marginale pelo teste ELISA indireto em amostras de colostro/leite e soro da búfala 130 e de seu bezerro (365) coletadas sequencialmente a partir do parto/nascimento, respectivamente. $-14^{*}=$ dias antes do parto e $1^{*}=$ dia do nascimento antes do bezerro mamar o colostro. Selvíria, MS, 2005. do parto, mas que declinaram durante os primeiros sete dias após, possivelmente em função da transferência de anticorpos para o colostro. Dos 21 dias ao término do monitoramento das búfalas, em torno dos cinco meses subseqüentes, os níveis ELISA ficaram acima do ponto de corte na maioria dos exames (NE variando de 3 a 6), principalmente para a búfala 134.

Quando se analisou o colostro destas duas búfalas (130 e 134) no ano 2005, verificou-se um resultado bastante diferente daquele observado no grupo de búfalas monitoradas em 1999. Ambas as búfalas tiveram anticorpos circulantes em níveis altos no dia do parto ( $\mathrm{NE}=7$ ), mas com queda abrupta já na primeira semana pós-parto (Tabelas 2 e 3 e Figuras 2 e $3)$. Cabe ressaltar que o anticorpo anti-A. marginale encontrava-se em alta concentração no soro antes do parto, mas com decréscimo acentuado no dia do mesmo (NE diminuindo de 6 e 7 para 3) em ambas as búfalas, significando uma transferência de anticorpos séricos para o colostro. Com relação aos bezerros, ambos apresentaram ausência de anticorpos séricos antes de mamarem o colostro, mas após o nascimento e 24 horas após mamarem o colostro, observou-se uma elevação nos níveis dos mesmos. Esta elevação ficou bem mais evidente no bezerro 366 (Tabela 3 e Figura 3), onde o nível de anticorpo alcançou o valor 5. Já o bezerro 365 (Tabela 2 e Figura 2), embora com NE levemente elevado, este não atingiu o ponto de corte. Esta elevação no nível de anticorpos significou uma aquisição de anticorpos colostrais de suas mães. No entanto, estes anticorpos declinaram já nos primeiros sete

Tabela 3. Anticorpos anti-Anaplasma marginale pelo teste ELISA em amostras de soros e colostros da búfala 134 e soros de seu bezerro (366), coletadas sequencialmente a partir do parto/nascimento, respectivamente. Dados em A/P (Amostra/Positivo) e NE (Níveis ELISA). Selvíria, MS, 2005.

\begin{tabular}{|c|c|c|c|c|c|c|}
\hline \multirow{4}{*}{$\begin{array}{c}\text { Dias } \\
\text { Pós-Nasci- } \\
\text { mento/Parto }\end{array}$} & \multicolumn{6}{|c|}{ Anticorpos anti-Anaplasma marginale - Valores A/P } \\
\hline & \multicolumn{4}{|c|}{ Búfala 134} & \multirow{2}{*}{\multicolumn{2}{|c|}{ Bezerro 366}} \\
\hline & \multicolumn{2}{|c|}{ Colostro } & \multicolumn{2}{|c|}{ Soro } & & \\
\hline & $A / P$ & $\mathrm{NE}$ & $A / P$ & NE & $A / P$ & NE \\
\hline-52 & & & 0,880 & 7 & & \\
\hline-15 & & & 0,262 & 3 & & \\
\hline$-1^{*}$ & & & 0,650 & 6 & $0,078^{*}$ & 0 \\
\hline 1 & 1,602 & 7 & 0,243 & 3 & 0,377 & 5 \\
\hline 7 & 0,211 & 0 & 0,357 & 3 & 0,221 & 3 \\
\hline 12 & 0,135 & 0 & 0,350 & 3 & 0,220 & 3 \\
\hline 21 & 0,196 & 0 & 0,631 & 6 & 0,127 & 1 \\
\hline 28 & 0,034 & 0 & 0,575 & 6 & 0,209 & 3 \\
\hline 34 & 0,006 & 0 & 0,326 & 4 & 0,073 & 0 \\
\hline 49 & 0,049 & 0 & 0,597 & 6 & 0,215 & 3 \\
\hline 56 & & & 0,590 & 6 & 0,213 & 3 \\
\hline 63 & & & 0,849 & 7 & 0,119 & 1 \\
\hline 70 & & & 0,466 & 6 & 0,232 & 3 \\
\hline 77 & & & 0,649 & 6 & 0,138 & 1 \\
\hline 92 & & & 0,849 & 7 & 0,282 & 4 \\
\hline 106 & & & 0,542 & 6 & 0,265 & 3 \\
\hline 119 & & & 1,145 & 8 & 0,143 & 1 \\
\hline
\end{tabular}

N: Número de animais. DP: Desvio padrão da média. -1-14 dias: dias antes do parto. 1*: dia do nascimento antes de mamar o colostro. Ponto de Corte $\geq 3$. 


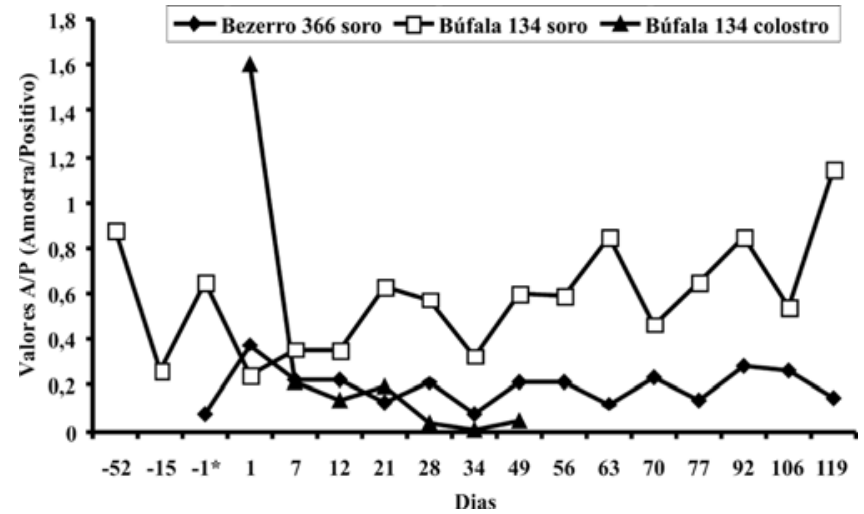

Figura 3. Anticorpos anti-Anaplasma marginale pelo teste ELISA indireto em amostras de colostro/leite e soro da búfala 134 e de seu bezerro (366) coletadas sequencialmente a partir do parto/nascimento, respectivamente. $-1,-15,-52$ dias antes do parto. $-1^{*}=$ dia do nascimento antes do bezerro mamar o colostro. Selvíria, MS, 2005.

dias após o nascimento para níveis $\mathrm{NE} \leq 3$, na grande maioria das amostras sanguíneas, até os 161 dias, quando finalizou o monitoramento sorológico destes bezerros. Embora, estes bezerros tenham recebido anticorpos colostrais de suas mães, a manutenção da resposta imune humoral foi fraca, pelo menos até o período analisado, estando de acordo com os resultados dos bezerros analisados em 1999/2000.

Estas diferenças na resposta imunológica frente a $A$. marginale entre os dois anos (1999/2000 e 2005), podem estar associadas a pequenas variações climáticas que ocorreram entre os dois períodos estudados. A região em estudo situa-se no noroeste do estado de São Paulo, onde a temperatura varia pouco entre os meses (com temperatura média anual em torno de $24^{\circ} \mathrm{C}$ ), mas a precipitação delimita duas estações, a seca (entre os meses maio a setembro) e a chuvosa (entre os meses de outubro a abril). No ano de 1999, no período seco, a precipitação pluvial mensal ficou abaixo dos $50 \mathrm{~mm}$ de chuva, mas no ano 2005, em alguns meses, durante o período seco, a precipitação alcançou $100 \mathrm{~mm}$, como nos meses de maio, agosto e setembro. Possivelmente, estas diferenças climáticas também interferiram na população dos vetores biológicos e mecânicos e consequentemente também na aquisição de A. marginale. No entanto, a quantificação de ectoparasitas nestes animais não foi realizada e desta forma, não foi possível realizar um estudo comparativo entre a infestação por carrapatos e a resposta imunológica. Contudo, os búfalos monitorados estavam clinicamente sadios, possivelmente em função da boa alimentação e do bom manejo recebido na Fazenda Experimental. Segundo Ristic (1981), a anaplasmose raramente é fatal para os bubalinos e os animais que sobrevivem à fase pré-patente da enfermidade, iniciam um processo de convalescença que pode durar de um a dois meses e criam uma sólida imunidade. A fonte de infecção, geralmente são animais infectados, que permanecem como portadores por vários anos.

Pode-se afirmar que os búfalos foram capazes de desenvolver resposta imune humoral contra A. marginale. Esta res- posta imune foi mais evidente nas búfalas do que nos bezerros, mas os bezerros, por outro lado, podem receber anticorpos colostrais de suas mães e também desenvolver posteriormente uma resposta imune adaptativa. Os búfalos foram considerados portadores sãos deste parasito.

Agradecimentos: A médica veterinária Dra. Eronides Marques de Souza, por coletar, organizar e armazenar os soros; ao Médico Veterinário Dr. Fernando Paes de Oliveira por colaborar na obtenção de sangue, juntamente com os funcionários da Fazenda Experimental da UNESP e finalmente a pesquisadora Gisele Andrade pelo auxílio na execução do ELISA.

\section{REFERÊNCIAS BIBLIOGRÁFICAS}

ALLINGHAM, P.G.; LEATCH, G.; KEMP, D.H. An attempt to transmit Anaplasma marginale by buffalo flies (Haematobia irritans exigua). Australian Veterinary Journal, v. 71, n.4, p. 122-123,1994.

AMERASINGHE, P.H.; VASANTHATHILAKE, V.W.; LIOYD, S.; FERNANDO, S.T. Periparturient reduction in buffalo of mitogen-induced lymphocyte proliferation and antibody to Toxocara vitulorum. Tropical Animal Health and Production, v. 26, n. 2, p. 109-116, 1994.

ANDRADE, G.M.; VIDOTTO, O.; VIDOTTO, M.C.; YOSHIHARA, E.; KANO, F.S.; AMARAL, C.H.S. Seroprevalence of Anaplasma marginale in dairy cattle and, studies on the dynamics of natural infection of Holstein calves in Southern Brazil. Semina: Ciências Agrárias, v. 22, n. 2, p. 155-159, 2001.

BARBET, A.F.; PALMER, G.H.; MYLER, P.J.; MCGUIRE, T.C. Characterization of an immunoprotective protein complex of Anaplasma marginale by cloning and expression of the gene coding for polypeptide AM 105L. Infection Immunology, v. 55, n. 10, p. 2428-2435. 1987.

CONNELL, M.L. Transmission of Anaplasma marginale by the cattle tick Boophilus microplus. Queensland Journal of Agricultural Animal Science, v. 31, p. 185-195, 1974.

COSTA, C.L.; KOHAYAGAWA, A.; DELL'PORTO, A.; BOMFIM, S.R.M. Determinação dos níveis de anticorpos anti-Babesia spp. em bezerros bubalinos (Bubalus bubalis), desde o nascimento até um ano de idade. Revista Brasileira de Parasitologia Veterinára, v.6, n. 2, p. 117-121, 1997.

FARIAS, N. A. R.; LEMOS, R. A. A. Tristeza Parasitária Bovina. In: LEMOS, R. A. A.; BARROS, N.; BRUM, K. B. Enfermidades de Interesse Econômico em Bovinos de Corte. Perguntas e Respostas. Campo Grande: UFMS, 2002. p. 199-209.

FRANZOLIN-NETO, R,; DELL'PORTO, A.; LACAZ RUIZ, R. Anaplasmosis and babesiosis: a clinical case in buffalo (Bubalus bubalis) calf in Brazil. Buffalo Bulletin, v.8, n.3, p. 54-68, 1989. 
FRANZOLIN-NETO, R. Perspectiva da Criação de Búfalos no Brasil. Aproveitamento Industrial de Búfalos. In: SAMARA, S.I.; DUTRA, I.S.; FRANCESCHINI, P.H.; MOLERO FILHO, J.R.; CHACUR, M.G.M (Eds.). Sanidade e Produtividade em Búfalos. Jaboticabal: FUNEP, 1993. p. 1-16.

FUENTE, J. DE LA; NARANJO, V.; RUIZ-FONS, F.; HÖFLE, U.; FERNÁNDEZ DE MERA, I. G.; VILLANÚA, D.; ALMAZÁN, C.; TORINA, A.; CARACAPPA, S.; KOCAN, K. M.; GORTÁZAR C. Potential vertebrate reservoir hosts and invertebrate vectors of Anaplasma marginale and A. phagocytophilum in central Spain. Vector-Borne and Zoonotic Diseases, v. 5, n.4, p. 390-401, 2005.

GALE, K.R.; LEATCH, G.; GARTSIDE, M.; DIMMOCK, C.M. Anaplasma marginale: failure of sera from immune cattle to confer protection in passive-transfer experiments, Parasitology Research, v.78, n. 5, p. 410-415, 1992.

GOMES, R.A.; STARKE-BUZETTI, W.A.; MACHADO, R.Z. Resposta imune-humoral de búfalos (Bubalus bubalis) infectados naturalmente por B. Bovis, B. bigemina e A. marginale. In: CONGRESSO BRASILEIRO DE PARASITOLOGIA VETERINÁRIA, 14, 2006, Ribeirão Preto. Anais..., Jaboticabal: CBPV. 2006. p. 312.

KANO, F.S.; VIDOTTO, O.; PACHECO, R.C.; VIDOTTO, M.C. Antigenic characterization of Anaplasma marginale isolates from different regions of Brazil. Veterinary Microbiology, v. 87, n. 2, p. 131-138, 2002.

KESSLER,R.H. Considerações sobre a transmissão de Anaplasma marginale. Pesquisa Veterinária Brasileira, v.21, n.4, p. 177-179, 2001.

KOCAN, K.M.; FUENTE, J. DE LA; BLOUIN, E.F.; GARCIA-GARCIA, J.C. Anaplasma marginale (Rickettsiales: Anaplasmataceae): recent advances in defining host-pathogen adaptations of a tickborne Rickettsia. Parasitology, v. 129, S285-S300, 2004.

LLOYD, S. Effect of pregnancy and lactation upon infection. Veterinary Immunology and Immunopathology, v. 4, n. 12, p. 153-176, 1983.

MACHADO, R.Z.; MONTASSIER, H.J.; PINTO, A.A.; LEMOS, E.G.; MACHADO, M.R.F.; VALADÃO, I.F.F.; BARCI, L.G.; MALHEIROS, E.B. An Enzyme-linked immunosorbent assay (ELISA) for the detection of antibodies against Babesia bovis in cattle. Veterinary Parasitology, v.71, n. 1, p. 17-26, 1997.

MASON, C.A; NORVAL, R.A.I. The transfer of Boophilus microplus (Acarina:Ixodidae: from infested to uninfested cattle under field conditions. Veterinary Parasitology, v. 8, n.2, p.185-188, 1981.

MIRANPURI, G.S. Tick parasitising the Indian buffalo (Bubalus bubalis) and their possible role in disease transmission. Veterinary Parasitology, v. 27, n. 3-4, p. 357362, 1988.
MOHAN, R.N. Diseases and Parasites of Buffaloes. III. Parasitic and miscellaneous diseases. Veterinary Bulletin, 38, p. 735-756, 1968.

NEWBY, T.J.; BOURNE, J. The nature of the local immune system of the bovine mammary gland. Journal of immunology, v.118, n.2. p. 461- 465, 1977.

PACHECO, R.C.; VIDOTTO, O.; TAMEKUNI, K.; IGARASHI, M.;KAWASAKI, P.; PRUDÊNCIO, L.B.; MARANA, E. R.M.; PEREIRA, A.L. Dinâmica da infecção natural pelo Anaplasma marginale em vacas e bezerros da raça Holandesa, na região de Londrina, Estado do Paraná, Brasil. Semina: Ciências Agrárias, Londrina, v. 25, n.3, p. 235-244, 2004.

PALMER, G.H. Anaplasma vaccines. In: WRIGHT, I.G. Veterinary Protozoan and Hemoparasite Vaccines. Boca Raton: CRC Press, 1989. p. 1-29.

POTGIETER, F.T.; SUTHERLAND, B.; BIGGS, H.C. Attempt to transmit Anaplasma marginale with Hippobosca ruptipes and Stomoxys calcitrans. Onderstepoort Journal Veterinary Research, v. 48, n. 2, p. 119-122, 1981.

RAJPUT, Z.I.; HU, SONG-HUA; ARIJO, A.G.; HABIB, M.; KHALID, M. Comparative study of Anaplasma parasites in tick carrying buffaloes and cattle. Journal of Zhejiang University Science, v. 6B, n.11, p. 1057-1062, 2005.

RISTIC, M. Anaplasmosis. In: RISTIC, M.; McINTYRE, I. Diseases of Cattle in the Tropics. Londres: Martinus Nijhoff, 1981. p. 327-344.

SASAKI, M.; DAVIS, C.L.; LARSON, B.L. Production and turnover for IgG1 and IgG2 immunoglobulins in the bovine around parturition. Journal of Dairy Science, v.59, n.12, p.2046-2055, 1976.

SHARMA, S. P. Characterization of Anaplasma marginale infection in buffaloes. Indian Journal Animal Science, v. 57, n. 2, p. 76-78, 1987.

SHIMADA, M., K.; YAMAMURA, M.H.; KAWASAKI, P.M.; TAMEKUNI, K.; IGARASHI, M.; VIDOTTO, O.; VIDOTTO, M.C. Detection of Anaplasma marginale DNA in larvae of Boophilus microplus ticks by polymerase chain reaction. Annals of the New York Academy of Sciences, v.1026, p.95 -102, 2004.

SOUZA, E.M. Resposta Imunológica de búfalos (Bubalus bubalis) naturalmente infectados com Toxocara vitulorum. 2001. 91 f. Dissertação (Mestrado) - Faculdade de Engenharia-Universidade Estadual Paulista, Ilha Solteira, 2001.

SRIVASTAVA, R.; AHLUWALIA, S.S. A clinical case of anaplasmosis in buffalo. Indian Veterinary Journal, v.51, n.5, p. 371-374, 1974.

STARKE, W.A.; ROCHA, U.F.; MACHADO, R.Z.; ZOCOLLER,M.C. Prevalence and intensity of infestation by Boophilus microplus (Canestrini, 1887), under natural conditions, in buffalos in Mato Grosso do Sul State, Brazil. In: CONFERENCE OF THE WORLD ASSOCIATION 
FOR THE ADVANCEMENT OF VETERINARY PARASITOLOGY, 11, 1985, Rio de Janeiro. Anais... Rio de Janeiro: CBPV, 1985. p. 10.

STARKE, W.A.; EVANGELISTA, F.M.M.; ZOCOLLER, M.C. Comparative study of the natural infestion by Boophilus microplus tick between buffalo and cattle. In: WORLD BUFALLO CONGRESS. 4, 1994, São Paulo. Anais... São Paulo: World Buffalo Breeding Association e
Sociedade Brasileira de Criadores de Búfalos, 1994. v. 2, p. 102.

YOSHIHARA, E.; VIDOTTO, O.; YAMAMURA, M.H.; MARANA, E.R.M.; PACHECO, R.; SILVEIRA, A.P. Studies of natural infection with Anaplasma marginale in nelore cattle in the Umuarama municipality, Paraná State, Brazil. Revista Brasileira de Parasitologia Veterinária, v. 12, n. 1, p. 21-26, 2003.

Recebido em 28 de dezembro de 2006.

Aceito para publicação em 30 de junho de 2008. 